\title{
Researchers combat resurgence of bed bug in behavioral studies and monitor trials
}

\author{
by Vernard R. Lewis, Sara E. Moore, \\ Robin L. Tabuchi, Andrew M. Sutherland, \\ Dong-Hwan Choe and Neil D. Tsutsui
}

The worldwide resurgence of bed bugs has recently created urban pest challenges in California. Regardless of information source - newspaper, Internet, television, university or government - the message is the same: bed bugs are back, and with a vengeance. Until recently, the pest's longstanding rarity and a historical reliance on pesticide-based management have not encouraged research and public education to develop and make available current information on bed bug biology, detection and control. UC is currently directing comprehensive, collaborative programs of research and education to combat this emerging nuisance and public health threat. Laboratory and field tests were conducted by $U C$ researchers on several commercial bed bug monitors and confirm that additional research is needed to improve the performance of existing monitors and to develop new ones.

\section{For centuries, and perhaps for millen- Hnia, bed bugs (Cimex lectularius [L.]} [Hemiptera, Cimicidae]) have been present in human habitations. Archeological evidence suggests these blood-sucking pests first plagued humans when they lived in caves (Usinger 1966). As people moved from caves into villages and cities, bed bugs also established themselves in the new human habitats. Throughout human history, accounts of infestations have been reported, irrespective of class or economic condition (Potter 2011). Bed bug infestations were frequently encountered in many parts of the world, including North America, for several decades into the 1900s (Cooper 2011; Potter 2011; Reinhardt and Siva-Jothy 2007).

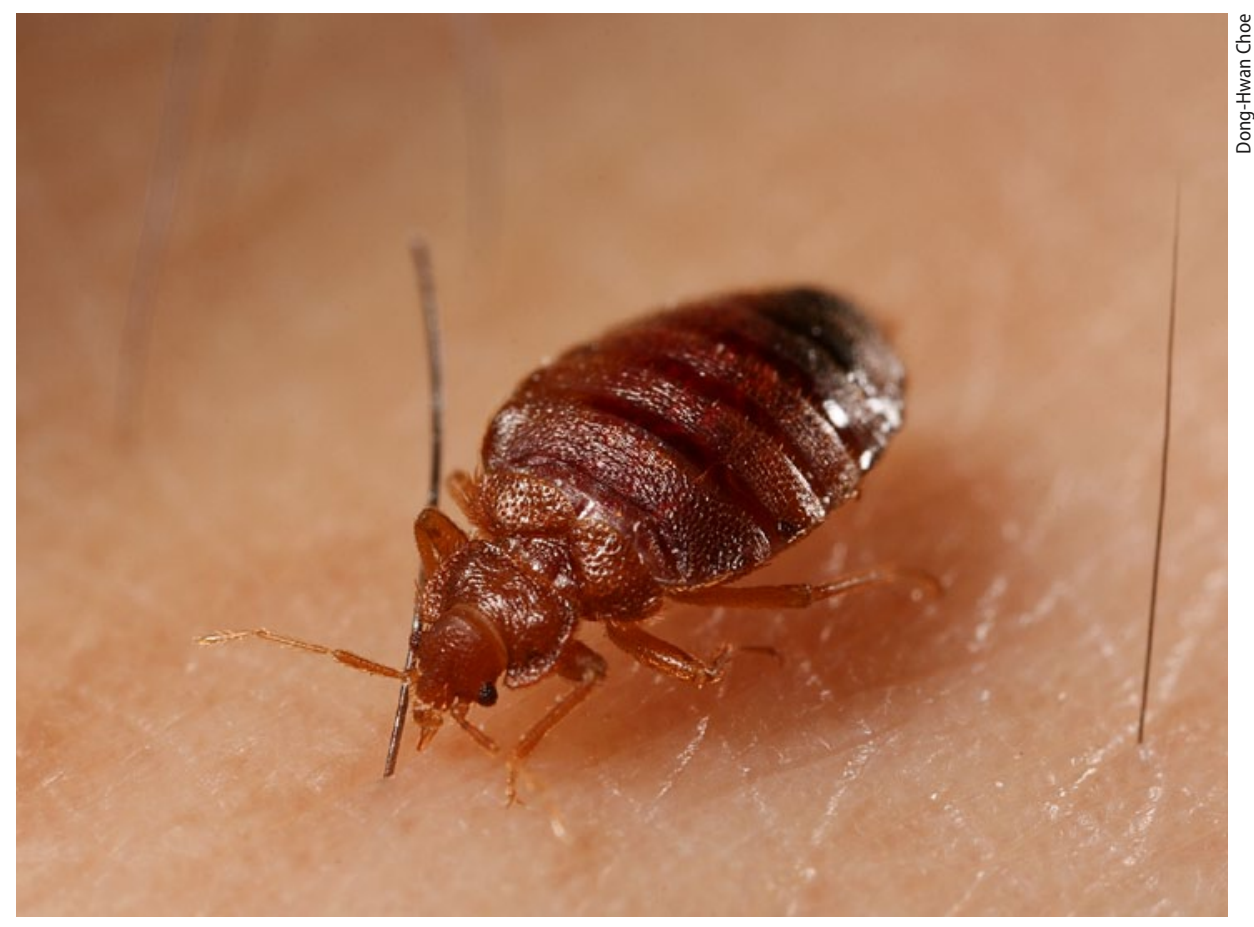

Accurately detecting bed bug infestations is crucial to the development of effective control strategies. In a recent study, UC researchers tested several commercial monitors for capture performance and found that additional research is needed to improve their effectiveness.

The decline in bed bug infestations started during World War II and was due, in part, to a control campaign that included the extensive use of the insecticide DDT (Ebeling 1978). This campaign included pest eradication for U.S. troop facilities (barracks, battlefield trenches, military-issued personal equipment, transport equipment and ships) as well as other public facilities throughout the world (Potter 2011). After the war, general improvements in household and personal cleanliness, along with widespread use of synthetic insecticides (primarily organochlorines and organophosphates) resulted in a dramatic reduction of bed bug infestations; bed bugs became rare, and infestations were restricted to areas afflicted with unsanitary conditions (Ebeling 1978; Snetsinger 1997).

\section{Why the resurgence?}

During the late 1990s, the first reports of resurgent bed bug infestations started to come from several parts of the world. Almost synchronic infestations were reported in England, Australia and North America (Boase 2001; Reinhardt and
Siva-Jothy 2007). Soon after these reports, documentation of the extent of the bed bug "plague" began to appear in U.S. pest control industry surveys (Potter et al. 2011). The sudden resurgence captured media attention, which highlighted the escalation of bed bug problems in university dorms, hospitals, theaters, hotels and public buildings in North America. Some reports even mentioned the closing of department stores due to bed bug infestations (Roberts and Burke 2010). The exact causes of the resurgence are not known, but important factors appear to include increased international travel among humans, pesticide resistance among bed bugs, the ease with which bed bugs can spread, and reduced indoor use of residual insecticides (Cooper 2011; Jones and Bryant 2012).

Bed bug resurgence in California has recently been reported by state and county public health officials (Lewis 2013),

Online: http://californiaagriculture.ucanr.edu/ landingpage.cfm?article=ca.v067n03p172\&fulltext=yes doi: 10.3733/ca.v067n03p172 
the pest control industry (Hopper 2010) and UC (Lewis 2013; Lewis et al. 2012, Sutherland et al. 2013). Media outlets in the state have featured articles and news segments on the "new" household pest (KGO-TV 2009; Los Angeles Times 2012).

Although state authorities, pest control industry representatives and UC scientists all agree that a significant increase in bed bug infestations has occurred, detailed surveys on the prevalence and intensity of infestations in hotels, apartments, college housing, public buildings and transportation facilities are still lacking. In response to the nationwide bed bug outbreak, the U.S. Environmental Protection Agency and U.S. Centers for Disease Control and Prevention issued a joint statement on the growing bed bug problem and need for control (CDC and EPA 2010).

The recent resurgence of bed bugs has public health implications, as well as economic and psychological impacts associated with infestations and bites. As a result, scientists have refocused their attention on understanding bed bug biology, ecology and management. Newly published molecular-based research has yielded clues about the origin of infestations and also about distribution patterns in the United States (Booth et al. 2012). The same paper confirmed results of a previous study showing that bed bug populations within a building are closely related, for instance within and between adjacent rooms or between apartments spanning multiple floors, and are likely dispersed inadvertently by humans (Wang et al. 2010). Additional recent studies have documented resistance to pyrethroid insecticides in several bed bug populations in the United States (Romero et al. 2009; Zhu et al. 2010) and the ineffectiveness of total-release aerosol foggers used in an attempt to eliminate bed bug infestations (Jones and Bryant 2012).

Other studies on bed bugs include the identification and description of airborne aggregation pheromones (Siljander et al. 2008), evaluation of the efficacy of canine detection (Pfiester et al. 2008) and evaluation of the performance of passive and active monitors (Wang and Cooper 2011, 2012; Wang, Gibb, Bennett, McKnight 2009; Weeks et al. 2010). Passive monitors are those that do not contain bed bug attractants (for instance carbon dioxide), while active monitors do contain such attractants.
Since the 1970s, only five new active ingredients (acetamiprid, chlorfenapyr, dinotefuran, hydroprene and imidacloprid) have been registered for and enjoyed wide use against bed bugs (Cooper 2011; Potter et al. 2011). The performance of integrated pest management (IPM) approaches and nonpesticidal methods (heat application) have also been the subject of recent reports (Naylor and Boase 2010; Pereira et al. 2009; Wang, Gibb, Bennett 2009).

\section{During the late 1990s, the first reports of resurgent bed bug infestations started to come from several parts of the world.}

\section{Research at Berkeley and Riverside}

The accurate and precise detection of bed bug infestations is a management challenge of long standing, yet it remains an essential first step in the development of any effective control strategy.

Chemical detection. At UC Berkeley, two of the authors (D.-H.C. and N.T.) tested the possibility that bed bug infestations can be detected by means of characteristic chemicals that are emitted by the pests. Bed bugs are extremely sensitive to body heat and chemical odors such as carbon dioxide and pheromones, and they rely on these cues when locating potential sources of blood meals and harborages.

Many studies have described a distinctive odor that bed bugs produce, and several volatile aldehydes have been identified from the insect's scent glands (Cooper 2011). To determine whether bed bugs do in fact produce diagnostic airborne odors, the authors captured samples of airborne volatile chemicals either on solid-phase

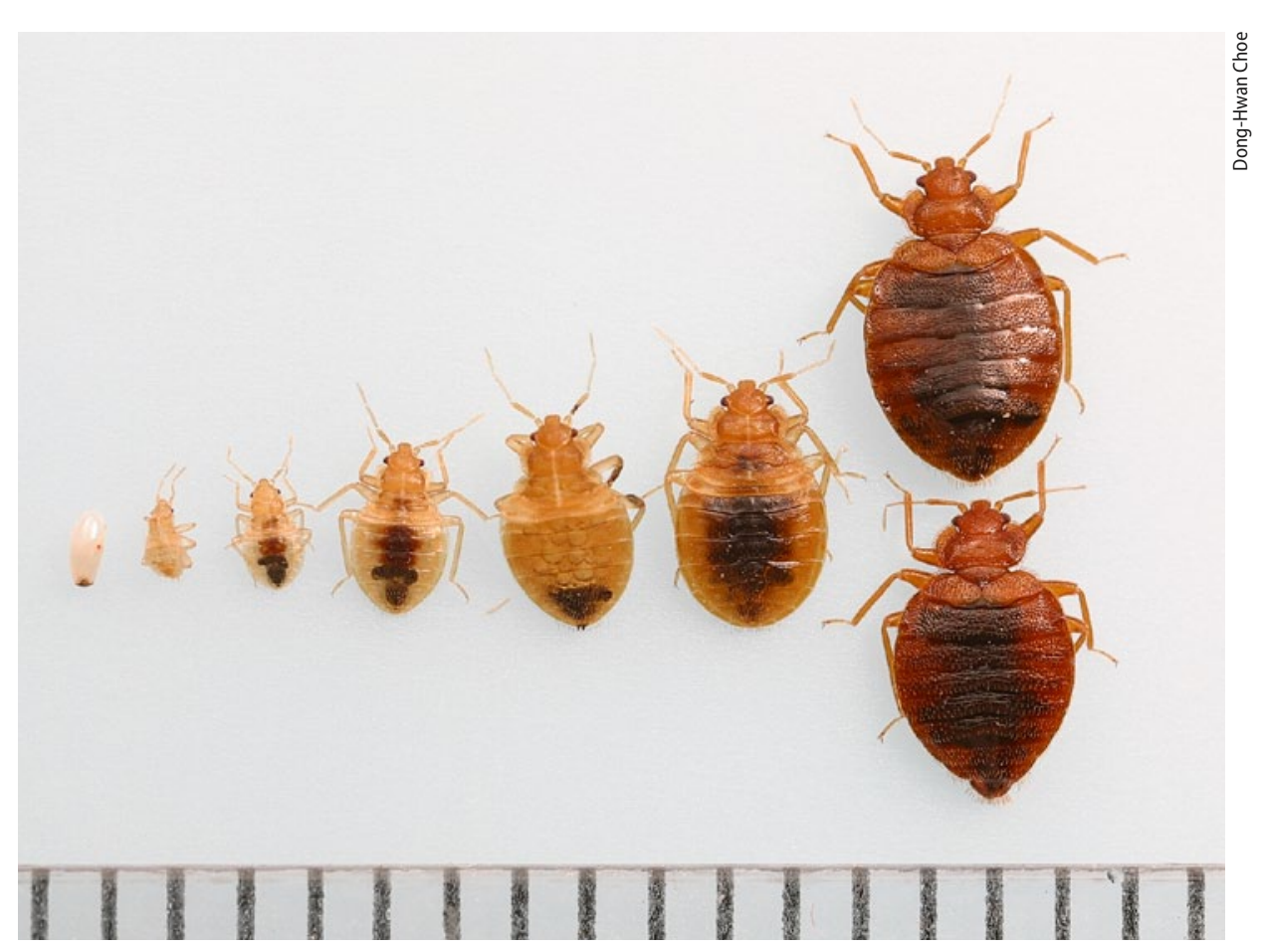

microextraction (SPME) fibers or on small charcoal-filter canisters. These samples were then extracted and analyzed using gas chromatography-mass spectrometry (GC-MS).

Under laboratory conditions, both SPME fibers and charcoal canisters were effective at capturing volatiles produced by bed bugs. No diagnostic volatile chemicals were evident when the researchers collected headspace samples from 10 adult bed bugs (in glass vials) that were not disturbed with the addition of carbon

The developmental stages for bed bugs, Cimex lectularius, are, from left to right, egg, nymphal instars 1 through 5 , and adult. The top adult is female, and the bottom is male. Adults are approximately 4 to 5 millimeters long (the diameter of a pencil eraser) and eggs are about 1 millimeter (the size of a grain of sand). The scale at the base is in millimeters. 
dioxide (fig. 1, green line). Significant amounts of 2-hexenal and 2-octenal were detected, however, when 10 adult bed bugs were disturbed with carbon dioxide (fig. 1, orange line). Subsequent quantitative analysis of the volatiles was conducted using varying numbers of bed bugs. First, carbon dioxide gas was injected into experimental shelters that contained different numbers $(0,1,5,10$ and 20) of bed bugs (fig. 2A). Immediately after injecting the gas, the volatiles were collected from each shelter using an activated charcoal volatile trap connected to a vacuum (fig. 2B). The activated charcoal volatile traps were extracted with methylene chloride containing an internal standard ( $n$-dodecane, $0.025 \mathrm{mg} / \mathrm{ml}$ ) to determine the relative abundances of the collected volatiles.

This study revealed a positive relationship between the number of bed bugs and the amount of 2-hexenal and 2-octenal detected (fig. 2). Although a single bed bug in a shelter could not be detected on this basis, the presence of five or more could easily be detected (fig. 2). Also, because these signature chemicals were detected at this high quantity only when live bed bugs were present in the shelters, this research might guide the development of a novel detection method for bed bugs hidden in items or locations for which visual inspection is either impossible or impractical (e.g., electronics). The research team is currently seeking funding support and collaboration opportunities with pest control industry and engineering experts to investigate the technical and commercial feasibility of this detection method.

Dog detectors. One of the authors (D.H.C.) has initiated two new bed bug research projects at UC Riverside since 2011. The first project focuses on training methods for bed bug detection dogs. Detection, or sniffer, dog use for bed bug inspection has become increasingly common in California and nationwide. However, the methods for training and handling the dogs vary considerably between companies and handlers, and this raises questions concerning the accuracy and reliability of the dogs' performance. The UC Riverside laboratory is currently exploring a new training method that uses only response to bed bug volatiles to measure a dog's detection performance. This new method, if successful, might eliminate the need to maintain live bed bug colonies for use in the continued training and conditioning of dogs.

Plant volatiles as fumigants. The second project addresses common concerns of the general public, including "What if I pick up bed bugs or eggs in my luggage while traveling?" and "How can I better protect myself and my home when I return, especially if I also have suspiciouslooking bites?" To help address these concerns, the UC Riverside laboratory is testing several plant-derived essential oil volatiles to determine their efficacy as fumigants against bed bug adults, nymphs and eggs. Some of these materials (for example, clove and wintergreen oil volatiles) are known to have adulticidal and ovicidal effects on other ectoparasites, such as head lice. These volatiles can be less toxic to humans than synthetic fumigants such as sulfuryl fluoride and dichlorvos, so this research may lead to the development of a relatively safe and possibly effective home remedy for bed bug infestations that involve smaller personal items such as purses, carriers and luggage bags. Also, these alternative materials might be useful in combating bed bug strains that are resistant to common synthetic insecticides. Lastly, an additional bed bug laboratory project involving an investigation of the possible effect of temperature on the insecticidal activity of plant essential oil volatiles is under way.

\section{Applying research: UC Berkeley}

For decades, there were no published reports that mentioned bed bug monitors. Only in the last few years has such research begun to appear in scientific journals. However, these studies were conducted in the eastern United States

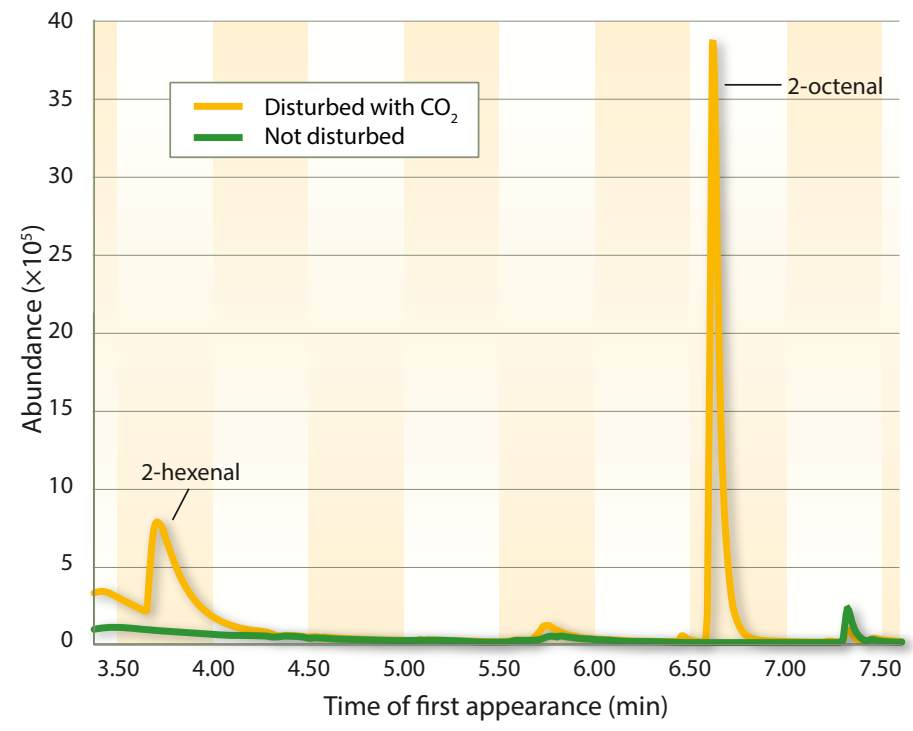

Fig. 1. Detection of bed bug-specific volatile chemicals, using SPME and GC-MS. The abundance (the sum of ion abundances, no unit) is represented on the $y$-axis and the retention time (time of first appearance of each compound) is represented on the $x$-axis.

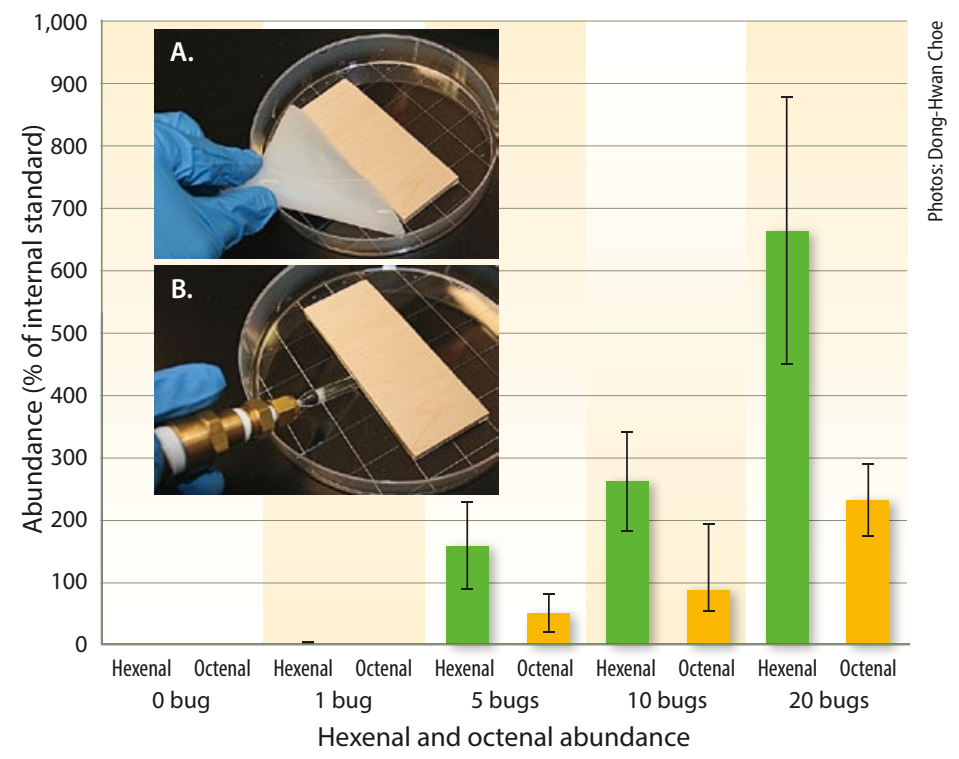

Fig. 2. Bed bug volatiles, collected from wooden shelters using an aeration device fitted with charcoal volatile traps. The abundance (mean \pm SEM) is expressed as a percentage of an internal standard ( $n$-dodecane, $0.025 \mathrm{mg} / \mathrm{ml}$ ). (A) Carbon dioxide gas was injected into shelters with different numbers of bed bugs. (B) The authors collected volatiles from the shelter using an activated charcoal volatile trap connected to a vacuum. 
in monitors and in or on furniture items. The active monitors captured approximately twice as many bed bugs as the passive monitors $(10 \%$ versus $5 \%$, respectively), but given the experimental design this was not a statistically significant difference $(F=0.21 ; D F=2 / 13 ; P>0.81)$. Females were spread over a larger area within the test arenas and items than were males (fig. 4).

Although highly variable, our capture rates among monitors were at least $2 \%$, and as high as $10 \%$ (active monitors), of the total number of bed bugs released in test arenas (fig. 3). However, capture performance could be enhanced if more monitors were used per unit of space, or if monitors were left out for a longer time, or if active monitors were used rather than passive monitors. Additional studies will be needed to determine differences in movement and foraging behavior among various strains of bed bugs in human habitats.

\section{Education and outreach}

One of the authors (A.M.S.) provides education and outreach for professional clientele engaged in pest management within the San Francisco Bay Area. These groups now have a special interest in bed bugs and their management since San Francisco has recently been identified as a hotspot of bed bug activity (Sutherland 2013). With this in mind, the author has begun collaborative research and outreach projects with local government agencies and professional pest control companies. Their collective goals are to demonstrate the effectiveness of education- and communication-based IPM programs for bed bug management, compare such IPM approaches to conventional bed bug management programs and provide effective management tools for difficult environments such as low-income and multiple-occupancy apartments. This author has also conducted training workshops for UC Cooperative Extension in the seven-county Greater Bay Area to increase their knowledge and confidence for dissemination of IPM-based information to the general public, recognizing bed bugs as a key pest in urban ecosystems.
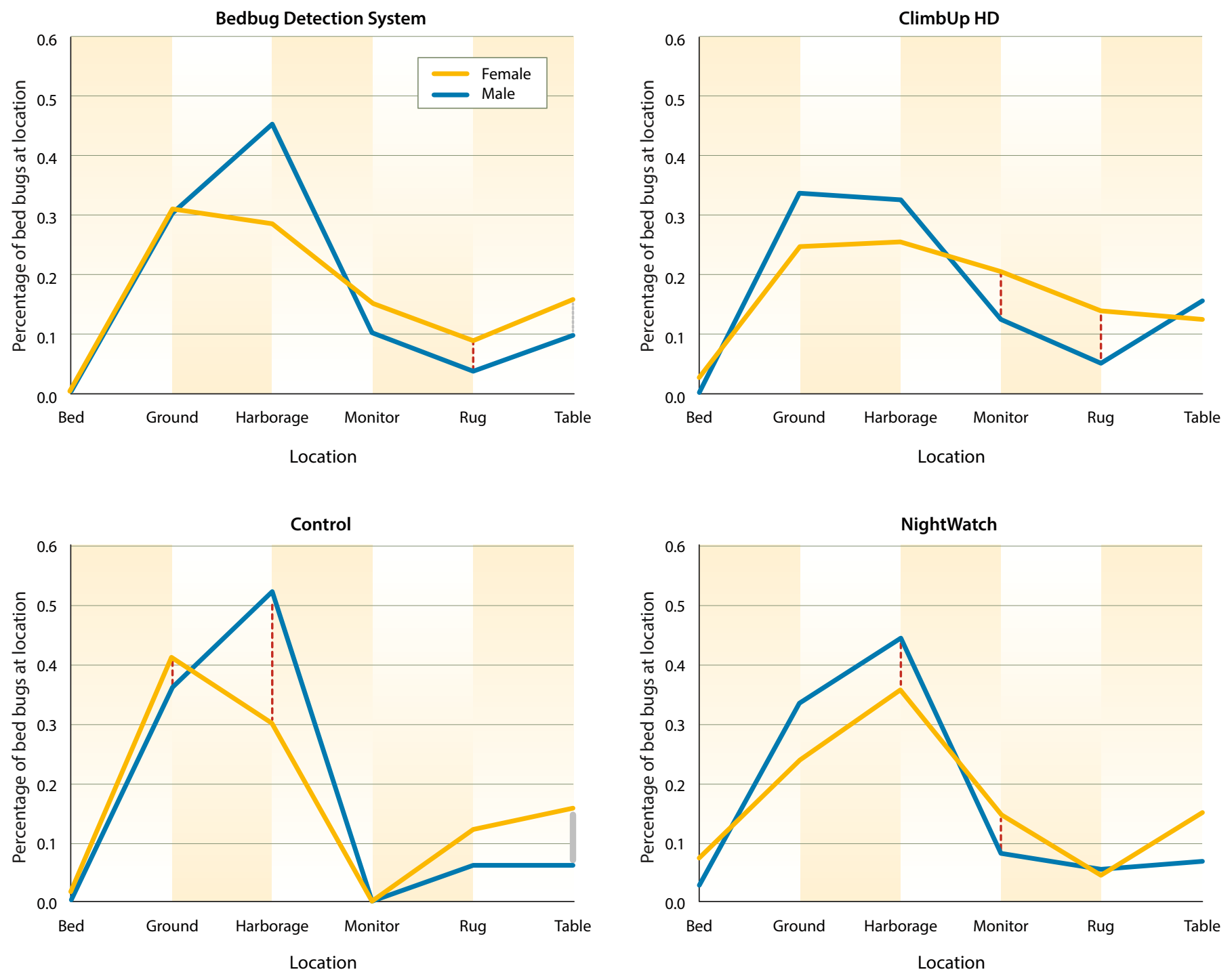

Fig. 4. Percentages of female and male adult bed bugs found in the various test arena locations in a study of three commercially available monitors plus a control. The vertical red dotted lines represent significant differences between male and female numbers (individual $t$-tests $>3$ and significance level $<5 \%)$. 


\section{Challenges and opportunities this decade}

The global movement of people and goods continues to increase at a rapid pace. This globalization allows the worldwide dissemination of pests, an effect that is particularly significant along the Pacific Rim, which includes California. Unfortunately, many pests - and bed bugs in particular — are opportunists that are very adept at hiding among human clutter and within human habitations, especially those with a high turnover rate (hotels and shortterm apartments, for instance); therefore, our urban centers are vulnerable to bed bug infestation. Meanwhile, the state of California has raised its pest control standards to embrace IPM approaches that provide effective pest management while at the same time safeguarding the environment by minimizing the use of pesticides and reducing the harmful effect of residual runoff into urban waterways.

Most experts agree that there is a bed bug problem in California, but additional research is needed to document the extent of the problem. Field surveys will be a daunting task, and will test the limits of any detection method. All currently available monitors will need additional testing, especially under field conditions. Two of the most important issues pertaining to bed bugs are verifying bites, instead of relying on complaints alone, and improving disclosure by reducing the stigma associated with admitting to, or being accused of, having them. However, existing science can't differentiate live bed bugs after

\section{Closer look: What if I suspect a bed bug infestation?}

W hile scientists agree there is a bed bug resurgence - as do Californians with first-hand experience - the extent of the problem is not fully known. Accurate monitors are still under development, especially where multi-unit dwellings are involved.

For several decades, UC entomologists and others did not need to manage bed bug populations. After World War II, during which DDT, organophosphate (OP) and organochlorine (OC) pesticides were developed, chemical treatments became standard and were widely effective across the country. Resistance by bed bugs to DDT first occurred in the 1950s. By the 1980s, U.S. manufacturers had ceased production of DDT and organochlorines. The replacement organophosphates were removed from public use in the 2000s, and the class of pesticides called pyrethroids are currently being phased out for public use.

As generations of pesticides were developed and used, resistant strains of bed bugs emerged and spread. Molecular studies indicate they have spread from Europe to the East Coast of the United States, and now from the East Coast to the West.

Once they are in a multiple-unit dwelling, bed bugs spread through inadvertent human carriers. Within a building, scientists have found bed bug populations are highly inbred. Bed bugs do not fly, but the immature stages are light enough and could be carried on a strong breeze. Humans can inadvertently carry them from room to room and floor to floor.

Eggs can cling to the bottom of a shoe and be carried to a new room, especially in carpeted areas. They can be moved on laundry carts or bed linens. While the adult bed bugs can be seen (they are a red color and the size of a small apple seed), the larvae upon hatching are 1 millimeter (the size of a grain of sand and a creamy whitish yellow color that is difficult to see).

Adult bed bugs can survive for up to 1 year without a blood meal, but once they sense carbon dioxide (which mammals emit as a result of respiration), they begin moving around, then homing in on the heat source and mammalian odors nearby, finding the human or animal present. They become more active at night, and the bites are not felt at first. Welts may develop the following day and generally redden; however, there is considerable variance in the response of humans to bites, so when in doubt about a skin irritation, it's best to consult your physician.

Home infestation. If you think you have a suspicious welt, you should consult your health care professional to confirm the causative agent. For additional information on bed bug biology and control, see Pest Notes: Bed Bugs, available at www.ipm.ucdavis.edu/PMG/ PESTNOTES/pn7454.html).

For severe infestations you should contact a professional pest management company local to your area. When

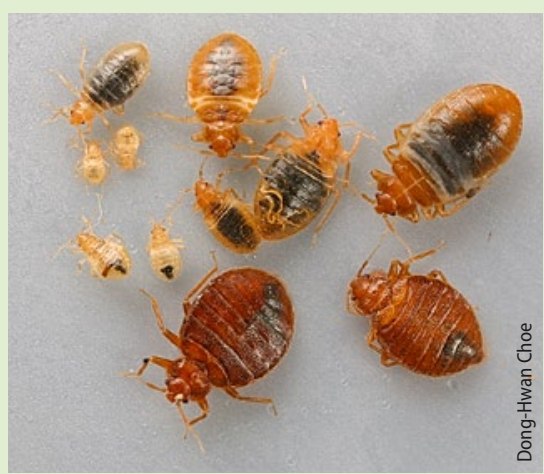

Bed bug nymphs and adults.

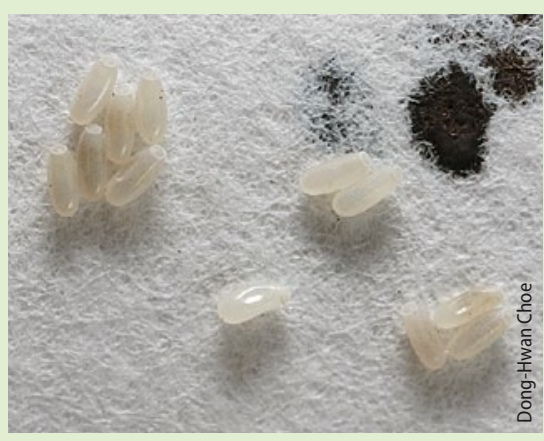

Bed bug eggs. cleaning bed linens and clothing items that may be infested, you will need to hot wash and then in a drying cycle at $140^{\circ} \mathrm{F}$ for at least 15 minutes.

Multi-unit dwelling infestation. If you find yourself in an apartment or dorm with bed bug problems, you will probably be asked to prepare your room for treatment by bagging and sealing your personal items in protective bags, moving large furniture items away from walls, and leaving your apartment or dorm room for treatment (up to several hours, depending on treatment).

If you are a manager or owner of such a dwelling, you will want to verify complaints by using monitors, and you will want to monitor not only the unit involved but the units next door and upstairs and downstairs. This is best done with active monitors that have documented success (for additional details, see Pest Notes: Bed Bugs, available at www. ipm.ucdavis.edu/PMG/PESTNOTES/pn7454. html).

- Janet White, based on research from Vernard Lewis 
a treatment from those that were recently brought in from an outside source. More accurate and discerning methods of bed bug detection and monitoring, proven in field tests, will better enable professionals and the public to make informed decisions regarding remedial treatment and prevention.

V.R. Lewis is UC Cooperative Extension Specialist, Department of Environmental Sciences, Policy and Management, UC Berkeley; S.E. Moore is Lab Technician and R.L. Tabuchi is Lab Manager for V.R. Lewis at UC Richmond Field Station; A.M. Sutherland is San Francisco Bay Area IPM Advisor with UCCE and UC IPM, Alameda County; D.-H. Choe is Assistant Professor and Assistant UCCE Specialist, Department of Entomology, UC Riverside; and N.D. Tsutsui is Professor and Agricultural Experiment Station Scientist, Department of Environmental Sciences, Policy and Management, and Faculty Curator, Essig Museum of Entomology, UC Berkeley.

The authors acknowledge Susan McKnight (ClimbUp Insect Interceptor), Robert Stockards (Atlantic Paste and Glue Co.), Ed Seitz (American
Exterminators), Stephen Racioppe (MidMos Solutions Ltd.), Aaron J. Sundholm (BioTrap Science) and David James (Packtite) for providing monitors used for testing. We also thank Gail Getty (Domus Institute) and Sylvia Kenmuir (Target Specialty Products) for technical assistance provided for our monitor research. We are also very appreciative of the contributions of Dr. James
Baldwin (USDA Forest Service, Albany, California) for statistical consulting, Dr. Michael Haverty for editorial assistance with earlier manuscript drafts, and David Huynh for laboratory assistance. Two UC bed bug studies mentioned in this article were funded by the California Structural Pest Control Board and the California Department of Pesticide Regulation (www.pestboard.ca.gov).

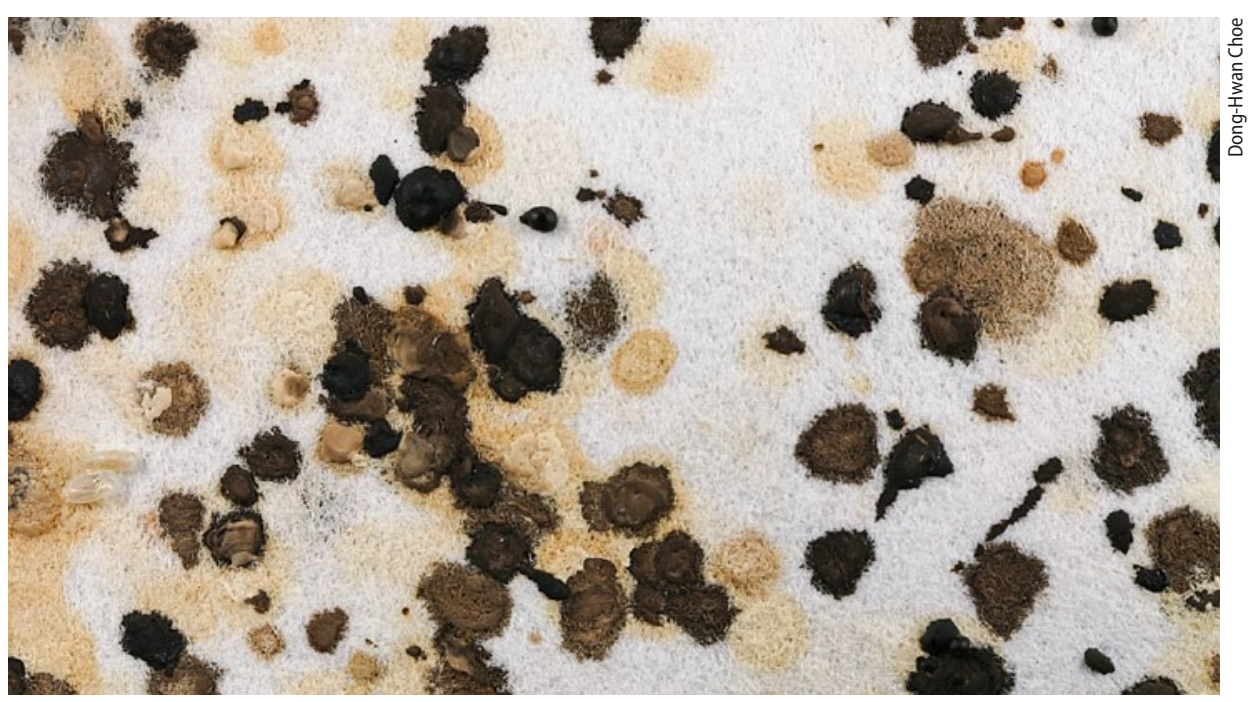

Bedbug fecal spots on a piece of white filter paper. Size of spot and color vary with bed bug size, meal and digestion time.

\section{References}

Boase C. 2001. Bedbugs: Back from the brink. Pestic Outlook 12(4):159-62.

Booth W, Saenz VL, Santangelo RG, et al. 2012. Molecular markers reveal infestation dynamics of the bed bug $(\mathrm{He}$ miptera: (imicidae) within apartment buildings. J Med Entomol 49(3):535-46.

[CDC] Centers for Disease Control and Prevention and [EPA] U.S. EnvironmentalProtection Agency. 2010. Joint statement on bed bug control in the United States from the U.S. Centers for Disease Control and Prevention (CDC) and the U.S. Environmental Protection Agency (EPA). Atlanta: U.S. Department of Health and Human Services. www.cdc.gov/nceh/ehs/Docs/Joint_Statement_on Bed_Bug_Control_in_the_US.pdf

Cooper R. 2011. Ectoparasites, part three: Bed bugs and kissing. In: Hedges S (ed.). Mallis' Handbook of Pest Control (10th ed). Richmond, $\mathrm{OH}$ : The Mallis Handbook Company. p 587-632.

Ebeling W. 1978. Bed bugs and allies (Cimicidae). In: Urban Entomology. Oakland, CA: UC Div Agric Sci, Berkeley, CA. p $463-75$.

Hopper MB. 2010. Bed Bugs... All Over! News Briefs, September 2010. West Sacramento, CA: Pest Control Operators of California, Inc.

Jones SC, Bryant JL. 2012. Ineffectiveness of over-the counter total-release foggers against the bed bug (Heteroptera: Cimicidae). J Econ Entomol 105(3):957-63.

KGO-TV. 2009. Bedbugs invade beds in the Bay Area. ABC7 News. San Francisco, CA. March 4, 2009.

Lewis VR. 2013. Bed bug: Present and future. The Voice of PCOC, Spring 2013. p 11-3.

Lewis VR, Moore S, Tabuchi R. 2012. Evaluation of Monitors for the Bed Bug, Cimex lectularius Linnaeus.

Sacramento, CA: Final Report Prepared for the California Structural Pest Control Board/Department of Pesticide Regulation. p 1-47. www.pestboard.ca.gov.
Los Angeles Times. 2012. L.A. places No. 5 on list of "Top 50 bed bug cities." March 21, 2012.

Naylor RA, Boase J. 2010. Practical solutions for treating laundry infested with Cimex lectularius (Hemiptera: Cimicidae). J Econ Entomol 103(1):136-9.

Pereira RM, Koehler PG, Pfiester M, Walker W. 2009. Lethal effects of heat and use of localized heat treatments for control of bed bug infestations. J Econ Entomo 102(3):1182-8.

Pfiester MP, Koehler G, Pereira RM. 2008. Ability of bed bug-detecting canines to locate live bed bugs and viable bed bug eggs. J Econ Entomol 101(4):1389-96.

Potter MF. 2011. The history of bed bug management with lessons from the past. Am Entomol 57(1):14-25.

Potter MF, Haynes KF, Rosenberg B, Henriksen M. 2011. 2011 bugs without borders (survey). Pest World Nov/ Dec:4-15.

Reinhardt K, Siva-Jothy MT. 2007. Biology of the bed bugs (Cimicidae). Ann Rev Entomol 52:351-74.

Roberts G, Burke C. 2010. Nike flagship store shut down, latest store to have bed bugs bite. New York Post, September 18, 2010

Romero A, Potter MF, Haynes KF. 2009. Evaluation of piperonyl butoxide as a deltamethrin synergist for pyrethroid-resistant bed bugs. J Econ Entomo 102(6):2310-15

Siljander E, Gries R, Khaskin G, Greis G. 2008. Identification of the airborne aggregation pheromone of the common bed bug, Cimex lectularius. J Chem Ecol 34:708-18.

Snetsinger R. 1997. Bed bugs and other bugs. In: Hedges $S$ (ed.). Mallis' Handbook of Pest Control (9th ed). Cleveland, OH: GIE Publishing. p 392-424.

Sutherland AM. 2013. Bed bug monitors enable early detection. Green Bulletin 3:1, 3
Sutherland AM, Choe DH, Lewis VR. 2013. Pest Notes: Bed Bugs. UC ANR Pub 7454. Oakland, CA.

Usinger R. 1966. Monograph of Cimicidae, vol. VII. Lanham, MD: Thomas Say Foundation, Entomological Society of America.

Wang C, Cooper R. 2011. Detection tools and techniques. Pest Contr Tech 39(8):72, 74, 76, 78-79, 112

Wang C, Cooper R. 2012. The future of bed bug monitoring. Pest World Jan/Feb: 4-9.

Wang C, Gibb T, Bennett GW, McKnight S. 2009. Bed bug (Heteroptera: Cimicidae) attraction to pitfall traps baited with carbon dioxide, heat, and chemical lure. J Econ Entomol 102:1580-5.

Wang C, Gibb T, Bennett GW. 2009. Evaluation of two least-toxic integrated pest management programs for managing bed bugs (Heteroptera: Cimicidae), with discussion of a bed bug intercepting device. J Med Entomol 46(3):566-71.

Wang C, Saltzmann K, Chin E, et al. 2010. Characteristics of Cimex lectularius (Hemiptera: Cimicidae): Infestation and dispersal in a high-rise apartment building. J Econ Entomol 103(1):172-7.

Weeks ENI, Birkett MA, Cameron MM, et al. 2010. Semiochemicals of the common bed bug, Cimex lectularius L. (Hemiptera: Cimicidae), and their potential for use in monitoring and control. Pest Manag Sci 67:10-20.

Zhu F, Wigginton J, Romero A, et al. 2010. Widespread distribution of knockdown resistance mutations in the bed bug, Cimex lectularius (Hemiptera: Cimicidae), populations in the United States. Arch Insect Biochem Phys 73(4):245-57. 